\title{
Optimum Design Parameters with the Lowest Cost of Basra Refinery Kettle Reboiler
}

\author{
Husam J. Alsaemre ${ }^{1}$, Adnan A. Ateeq ${ }^{2}$, and Ali N. Kalaf ${ }^{3}$ \\ Eng.hussam1980@gmail.com ${ }^{1}$, Adnan_ateeq@stu.edu.iq ${ }^{2}$, alinasiralmajed@gmail.com ${ }^{3}$
}

Department of Thermal Mechanical Engineering, Southern Technical University, Basra, Iraq ${ }^{1,2}$

Department of Chemical Engineering, College of Engineering, University of Basra, Basra, Iraq ${ }^{3}$

\begin{abstract}
Operating a kettle reboiler on high efficiency has been the foci of this study. In this study, an attempt to choose the best design parameters and the optimal operating conditions to attain the highest efficiency while maintaining the annual cost at the lowest. Aspen plus ${ }^{\circledR}$ and Aspen exchanger design and rating (EDR)® software V10 were implemented for design simulation and optimization calculations to control those factors connected to heat transfer coefficient, which is an indication of the efficiency. The study used to apply techniques on the kettle reboilers available in enhancing the gasoline unit in Southern Refinery Company in Iraq. A conclusion found that cast iron is the best metal type while the suitable diameter is found $25.4 \mathrm{~mm}$ and optimum operating conditions was $493 \mathrm{k}$ and $4 \mathrm{~kg} / \mathrm{s}$, the temperature of cold in-stream and mass flow rate of the fluid entering the hot stream respectively, this yields to increase the efficiency by $28.27 \%$.
\end{abstract}

Keywords: Kettle reboiler, Aspen Plus ${ }^{\circledR}$, Aspen EDR®, simulation, optimization, Heat exchanger.

\section{Introduction}

Reboilers are heat exchangers commonly used to heat the bottoms of industrial distillation columns are generally utilized in the petroleum industry. Since distillation is such a critical process in the petroleum, petrochemical, and chemical industries, the effective-reboiler operation is also necessary when a liquid might also need to be vaporized for various reasons, especially when a liquid feed is needed to be vaporized before entering a reactor. Normally, the liquid boils inside the shell by the effect of hot fluid flows in the tube side. The contact-liquid flows in the outer surface area of the tube will change their phase by receiving the latent heat transfer from the tube side, the vapor that produces will be used in the specific process for the reason which the reboilers was manufactured. The design of a reboiler is determined by the type and uses of the process to select the correct and suitable one. Reboiler classified according to the circulation type into forced and Natural circulation[1]. The use of a specific type of reboiler for a specific operation must first be through a full knowledge of the types of reboilers, their classification, advantages, and disadvantages of each type [2]. The simulation will now be carried out in almost all the areas of sciences and especially in engineering. It is important to improve and optimize the design, chemical, and physical properties used in the simulation program's approach can be calculated using statistical models. Heat exchangers with the same surface area but a different height and diameter produce a different average heat transfer coefficient [3]. a model for simulating the fluid dynamics and pillow plate thermal performance thermosiphon of reboilers' correlations for the single-phase heat transfer coefficient were used, the heat transfer coefficient with nucleate boiling was calculated [4]. Kettles reboiler with two phases flow was simulated in two dimensions, the one-fluid model was created. The one fluid model demonstrated that tube liquid evaporation can occur often at low heat flux than the earlier assumed and that the fluid kinetic energy required to cause tube vibrations was much lower than previously occurred [5]. A 241-tube thin slice kettle reboiler was used to study the two-phase flow phenomenon when boiling R113 and n-pentane, it was discovered that the height of the row pressure drop distribution in each column was unaffected by the mixture [6]. A kettle reboiler shell side thermal hydraulics simulation and analysis were shown. The computational fluid dynamics approach (CFD) was used to present the model. The main finding was that in mixture models, simulating the slip between liquid and gas-phase velocity, or simulating the interface friction model in two-fluid models, had a substantial influence on the void fraction distribution and two-phase flow area. [7]. Presented a simulation of a kettle reboiler. A hydrodynamic model has been developed using a rectangular tube sheet. Results demonstrate that the rate of the reboiler recirculation has been shown to differ with the heat flux and pressure. Furthermore, mass flux and heat transfer coefficient has shown steadily rising from the bottom to the top tube row of the package at a known value of heat flux and pressure vapor quality [8]. A simple model that split the evaporator into two parts (region for heating and evaporation) described the results of all of these parameters. The operating characteristics of these two zones are determined by the length differences of these two zones [9]. The 
repercussions of these recasting for the Data from thin-sliced rigs were used to determine the design of full-scale kettle reboilers, moreover, Shell side evaporators recirculation was discussed, which has been done by used 241 tubes package kettle reboiler thin slice device [10]. Under the multiple objective optimizations scheme, an improved version of the genetic algorithm was used for this. This optimization method was used to locate a set of optimal points identified as the Pareto-optimal set [11]. Used the Aspen HYSYS simulation software to simulate and optimize a crude oil distillation plant in a refinery to increase the unit's performance. The simulation-derived optimum operating conditions improved the plant's performance, resulting in higher kerosene and naphtha produces [12]. An optimized model for dropping film from plate-fin condenser-reboilers, the suggested geometrical optimization method, and analysis results could provide technical guidelines for designing and optimizing actual falling film from plate-fin condensers-reboilers and other falling film type plate-fin heat exchangers for cryogenic device applications[13]. This research includes studying the influence of factors that affect optimal performance and the cost of kettle reboiler that is used in enhancing gasoline units in Southern Refinery Company in Iraq.

\section{Process Description}

Since the purpose of the study is to increase the performance and efficiency of the reboiler through simulation by using the Aspen Plus ${ }^{\circledR}$, Aspen EDR $®$ program V 10, the design of projects and the calculation of the equipment cost through AspenTech items depend on a predefined design and cost considerations, the costs are described in the cost estimate database of AspenTech, where the AspenTech program also identifies the construction metals, handling, and landing costs, in which the latest versions or with old versions, the AspenTech cost calculation foundation and database are updated usually.

For that reason, this study clarifies the relationship of all variables and factors that affect the increase in performance and efficiency, whether mechanical or thermal, to reach the optimal design, as well as taking into consideration the design cost, where a case study of a kettle reboiler was taken from Southern Refinery Company, the procedure done by the following steps:

1- Aspen Plus simulation for kettle reboiler: Aspen Plus V 10 was used to simulate a kettle reboiler, the chosen components in the hot stream (tube side) were benzene and hydrogen (1\% mole fraction), and in the cold stream (shell side) was benzene, the table (1) represents the data of the operation condition (pressure, temperature, and mass flow rate) and the basic design information that has been taken from the case study in the enhancement benzene unit at the southern refinery company which is used as input for the simulation in the program. Benzene is a mixture of petroleum components that consists of 36 materials for the cold stream and 38 materials for the hot stream.

The components that were used were selected in the databank of the program and the ratio of composition of components was input for the cold and hot streams. The fluid package that was used in the simulation model was the Peng-Robinson equation of state, which is the suitable method that can be used to calculate the properties (such as the enthalpy, entropy, etc.) of fluid or fluid-mixture. Figure (1) show the simulation environment of the kettle reboiler and the input data in Aspen Plus.

Table 1: Data for Operation Conditions

\begin{tabular}{|c|c|c|c|c|}
\hline \multicolumn{5}{|c|}{ Data for Hot Stream (Tube): BENZENE $+\mathrm{H}_{2}$} \\
\hline \multicolumn{3}{|c|}{ IN } & \multicolumn{2}{|c|}{ OUT } \\
\hline $\mathrm{P}$ & 35.97 & bar & 35.928 & bar \\
\hline $\mathrm{T}$ & 788 & $\mathrm{k}$ & 568 & $\mathrm{k}$ \\
\hline $\mathrm{m}^{*}$ & 3.055 & $\mathrm{~kg} / \mathrm{s}$ (vap.) & 3.055 & $\mathrm{~kg} / \mathrm{s}$ (vap.) \\
\hline \multicolumn{5}{|c|}{ Data for Cold Stream (Shell): BENZENE } \\
\hline \multicolumn{3}{|c|}{ IN } & \multicolumn{2}{|c|}{ OUT } \\
\hline $\mathrm{P}$ & 25.83788 & bar & 25.668 & bar \\
\hline $\mathrm{T}$ & 503 & $\mathrm{k}$ & 505 & $\mathrm{k}$ \\
\hline $\mathrm{m}^{*}$ & 20.48 & kg/s (liq.) & 11.8675 & $\mathrm{~kg} / \mathrm{s}$ (vap.) \\
\hline
\end{tabular}


(18), $\mathrm{H}$ 月・

Simulation 1 - Aspen Plus V10 - aspenONE

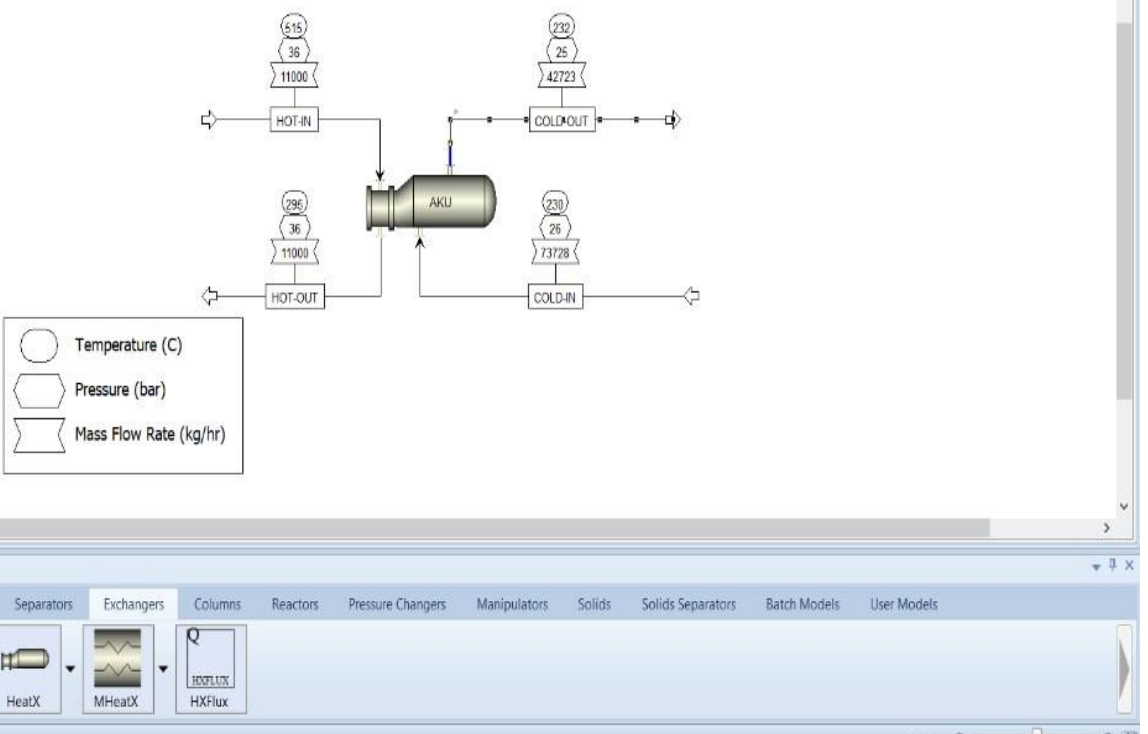

Fig. (1): The Simulation of Kettle Reboiler Using Aspen Plus.

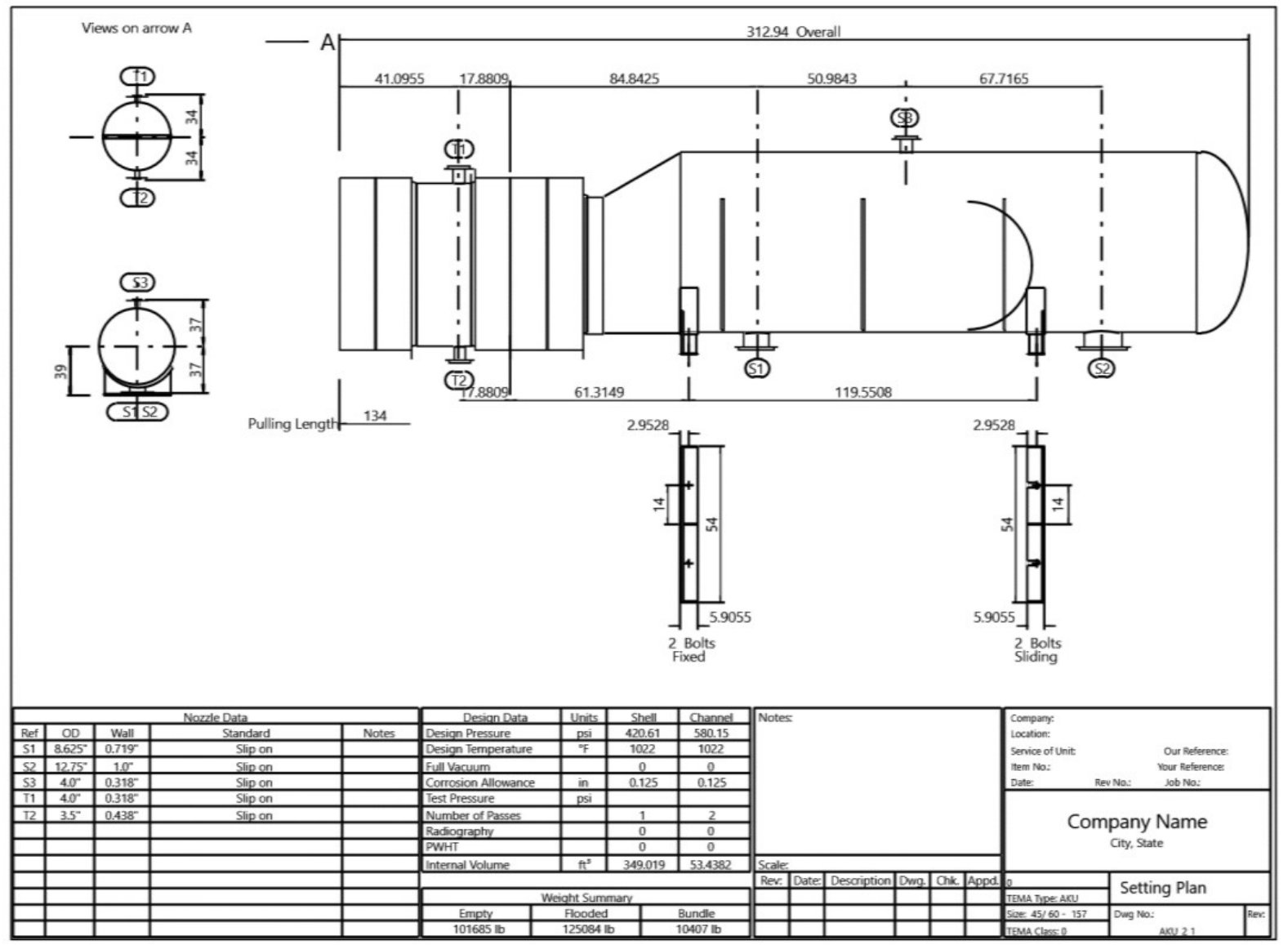

Fig. (2): The Simulation of Kettle Reboiler Using EDR. 
2- Aspen exchanger design and rating (EDR): Critical methods are sizing new equipment and rating existing equipment to provide sufficient space and selecting the right exchanger type for given use as shown in Fig 2. At a given set of process parameters, this will result in the most costeffective heat exchanger configuration. This broad variety of device requirements is addressed by Aspen EDR and they're useful for both the infrastructure contractor and the equipment fabricator, enabling models to be moved from prototype to practical troubleshooting. EDR is used to design the heat exchanger after the information data of the flow rate and temperature were obtained for the hot and cold streams in Aspen Plus where EDR used these data for calculations. The mechanical data that used in the modeling simulation in design the kettle reboiler by EDR is that for the internal and outside shell diameter is 1150 and $1200 \mathrm{~mm}$ respectively and for the tube, the number of the tube is 200 with an internal diameter of $25 \mathrm{~mm}$ and a thickness of $2.5 \mathrm{~mm}$ also $4000 \mathrm{~mm}$ length and using a tube pitch of $32 \mathrm{~mm}$.

3- Simulation of design variable: In this research, the effect of a set of design and operational variables on the kettle reboiler was studied, take a case study of a kettle reboiler located in the Southern Refinery Company at the gasoline enhancing unit. Table (2) below represents the simulation result from the Aspen Plus program. The kettle reboiler design calculation equations were also compared with the results of the Aspen Plus program and EDR, and the effects of design variables on costs were also calculated during those operations.

Table 2: The Simulation Result by Aspen Plus.

\begin{tabular}{|c|c|c|c|c|}
\hline \multicolumn{5}{|c|}{ Data for Hot Stream (Tube): BENZENE $+\mathrm{H}_{2}$} \\
\hline \multicolumn{3}{|c|}{ IN } & \multicolumn{2}{|c|}{ OUT } \\
\hline $\mathrm{P}$ & 35.97 & bar & 35.928 & bar \\
\hline $\mathrm{T}$ & 788 & $\mathrm{k}$ & 568 & $\mathrm{k}$ \\
\hline$\lambda$ & 170.3 & \multicolumn{3}{|c|}{$\mathrm{kJ} / \mathrm{kg}$} \\
\hline$\rho$ & 5.721 & \multicolumn{3}{|c|}{$\mathrm{kg} / \mathrm{m}^{3}$} \\
\hline$\mu$ & 0.023 & \multicolumn{3}{|c|}{$\mathrm{cP}$} \\
\hline$=$ & 0.000023 & \multicolumn{3}{|c|}{ N.s $/ \mathrm{m}^{2}$} \\
\hline $\mathrm{k}$ & 0.931 & \multicolumn{3}{|c|}{$\mathrm{W} / \mathrm{m} . \mathrm{k}$} \\
\hline $\mathrm{C}_{\mathrm{p}}$ & 3.932 & \multicolumn{3}{|c|}{$\mathrm{kJ} / \mathrm{kg} \cdot \mathrm{k}$} \\
\hline $\mathrm{m}^{\cdot}$ & 3.055 & $\mathrm{~kg} / \mathrm{s}$ (vap.) & 3.055 & $\mathrm{~kg} / \mathrm{s}$ (vap.) \\
\hline \multicolumn{5}{|c|}{ Data for Cold Stream (Shell): BENZENE } \\
\hline & IN & & OUT & \\
\hline $\mathrm{P}$ & 25.83788 & bar & 25.668 & bar \\
\hline $\mathrm{T}$ & 503 & $\mathrm{k}$ & 505 & $\mathrm{k}$ \\
\hline $\mathrm{m}^{\circ}$ & 20.48 & kg/s (liq.) & 11.8675 & kg/s (vap.) \\
\hline $\mathrm{P}_{\mathrm{c}}$ & 33.83 & \multicolumn{3}{|c|}{ bar } \\
\hline $\mathrm{P}$ & 25.837 & \multicolumn{3}{|c|}{ bar } \\
\hline
\end{tabular}

4- Create a structure of a thermo-hydraulic design strategy (mathematical model), The mathematical model's purpose is to figure out the overall heat transfer coefficient, the heat exchanged area required, number of tubs, and heat duty for the kettle reboiler The design equation [14] that used as follows:

Where $(1.05=5 \%$ of heat losses $)$

$$
\text { Heat Duty }(\varnothing): \varnothing=m * \lambda * 1.05
$$

Mean temperature difference $\left(\Delta \mathrm{T}_{\mathrm{m}}\right): \Delta \mathrm{T}_{\mathrm{m}}=\Delta \mathrm{T}_{\mathrm{ln}} * \mathrm{~F}$

$$
\Delta T_{l n}=\frac{\Delta \mathrm{T} 1-\Delta \mathrm{T} 2}{\Delta \mathrm{T} 1}
$$

The exchanger required area $\left(\Delta \frac{\Delta \mathrm{T} 1}{\Delta \mathrm{T} 2}\right.$ 


$$
A=\frac{\emptyset}{U_{o} \Delta T_{m}}
$$

No. of Tubes (Nt):

$$
\mathrm{Nt}=\frac{\mathrm{A}}{\pi * \mathrm{Do} * \mathrm{~L}}
$$

The number of tubes pass (NP)

$$
\mathrm{N} \text { pass }=\frac{\mathrm{Nt}}{2}
$$

Cross-section area $(\mathrm{AC})$

$$
\text { A cross }=\frac{\pi *(\mathrm{Di})^{2}}{4}
$$

Area pass: Apass $=$ Npass $*$ A cross

Velocity in tubes(v):

$$
\mathrm{v}=\frac{\mathrm{m}^{\cdot}}{\rho * \text { A pass }}
$$

Reynolds Number (Re):

$$
\mathrm{Re}=\frac{\rho * \mathrm{v} * \mathrm{Di}}{\mu}
$$

Shell side boiling coefficient $\left(h_{0}\right)$ from Mostinski Equation:

$$
\mathrm{h}_{0}=0.104 * \mathrm{Pc}^{0.69} *\left(\frac{\emptyset}{\mathrm{A}}\right)^{0.7} *\left[1.8\left(\frac{\mathrm{P}}{\mathrm{PC}}\right)^{0.17}+4\left(\frac{\mathrm{P}}{\mathrm{PC}}\right)^{1.2}+10\left(\frac{\mathrm{P}}{\mathrm{Pc}}\right)^{10}\right]
$$

Prandtl Number (pr):

$$
\operatorname{Pr}=\frac{\mathrm{cp} * \mu}{\mathrm{K}} \quad, \text { where Nusselt number }=\frac{\mathrm{hi} * \mathrm{Di}}{\mathrm{K}}
$$

Tube side heat transfer coefficient $(h i)$

$$
\frac{\mathrm{hi} * \mathrm{Di}}{\mathrm{K}}=0.23 * \mathrm{Re}^{0.8} * \operatorname{Pr}^{0.3}
$$

The overall heat transfer coefficient $\left(\mathrm{U}_{0}\right)$ :

$$
\mathrm{U}_{0}=\frac{1}{\frac{1}{\mathrm{~h}_{0}}+\frac{1}{\mathrm{hod}}+\frac{\mathrm{Do} *\left(\ln \frac{\mathrm{Do}}{\mathrm{Di}}\right)}{2 \mathrm{~K}_{\mathrm{w}}}+\left(\frac{\text { Do }}{\mathrm{Di}} * \frac{1}{\mathrm{hid}}\right)+\left(\frac{\text { Do }}{\mathrm{Di}} * \frac{1}{\mathrm{hi}}\right)}
$$

Where $\left(\mathrm{K}_{\mathrm{w}}\right)$ is the thermal conductivity of tube metal.

5- Model validation: Validation is the procedure of verifying whether the simulating and the modeling and their related results are matching the results of the mathematical model, This comparison between the simulation and mathematical model is very important to verify these results. Table (3) shows a comparison between the Aspen Plus results obtained from the simulation and the mathematical model (design equation) we notice a great convergence between the results in the two cases, and this indicates that the simulation results are valid and reliable in design calculations, with an acceptable error margin of $7.1 \%$ for the overall heat 
transfer coefficient, $1.3 \%$ for the heat exchanged, $0.43 \%$ for heat exchanged area and $0.25 \%$ for the number of tubes.

Table 3: The Model Validation

\begin{tabular}{|l|c|c|}
\hline \multicolumn{1}{|c|}{ Design Parameters } & Aspen Plus Calculations & Design Equation Calculations \\
\hline Number of tubs & 200 & 200 \\
\hline Heat exchanged area & $62.3 \mathrm{~m}^{2}$ & $62.57 \mathrm{~m}^{2}$ \\
\hline Heat exchanged & $2094.3 \mathrm{~kW}$ & $2122.087 \mathrm{~kW}$ \\
\hline overall heat transfer coefficient & $361.7 \mathrm{~W} / \mathrm{m}^{2} . \mathrm{k}$ & $335.76 \mathrm{~W} / \mathrm{m}^{2} . \mathrm{k}$ \\
\hline
\end{tabular}

\section{Result and discussion}

Many parameters affect the tube design of the kettle reboiler and that's led to reflected in the overall design and cost. In this section the mechanical and thermal variable design will discuss as follow:

3.1 Effect of tube diameter: The table below (4) shows that the change of tube diameter reflects on the area which makes a change in heat exchanged, overall heat transfer coefficient, mean temperature difference, which led to an impact on the cost. The marked with red row represents the simulation of the case study in which its result will be adopted in this study. And it's clear that the smaller the diameter of the tube is the greater heat exchanged and overall heat transfer coefficient as shown in Figure (3). The cost calculation is shown in appendix (1) which demonstrates the cost calculation by the EDR program. Increasing the heat transfer coefficient as the tube diameter decreases, because reducing the tube diameter raises the fluid flow velocity, which increases the Reynolds number, thus boost the Nselt number, which increases the heat transfer coefficient.

Table 4: Tubes Diameter Change and Its Effects.

\begin{tabular}{|c|c|c|c|c|}
\hline $\begin{array}{c}\text { Tube Dia. } \\
\mathbf{m m}\end{array}$ & $\begin{array}{c}\text { Area } \\
\mathbf{m}^{\mathbf{2}}\end{array}$ & $\begin{array}{c}\text { Heat Exchanged } \\
\mathbf{k W}\end{array}$ & $\begin{array}{c}\mathbf{U}_{\mathbf{0}} \\
\mathbf{W} / \mathbf{m}^{\mathbf{2}} \cdot \mathbf{k}\end{array}$ & $\begin{array}{c}\text { Total Cost } \\
\mathbf{U S D} \mathbf{\$}\end{array}$ \\
\hline 12.7 & 31.8 & 2146.4 & 1133.6 & 275181 \\
\hline 15.88 & 39.5 & 2138.4 & 782.5 & 275727 \\
\hline 19.05 & 47.4 & 2124.7 & 572.7 & 276254 \\
\hline 22.22 & 55.3 & 2108.1 & 438.8 & 276580 \\
\hline 25.4 & 62.3 & 2094.3 & 361.7 & 277088 \\
\hline 28.58 & 71.2 & 2076.7 & 288.2 & 277712 \\
\hline
\end{tabular}

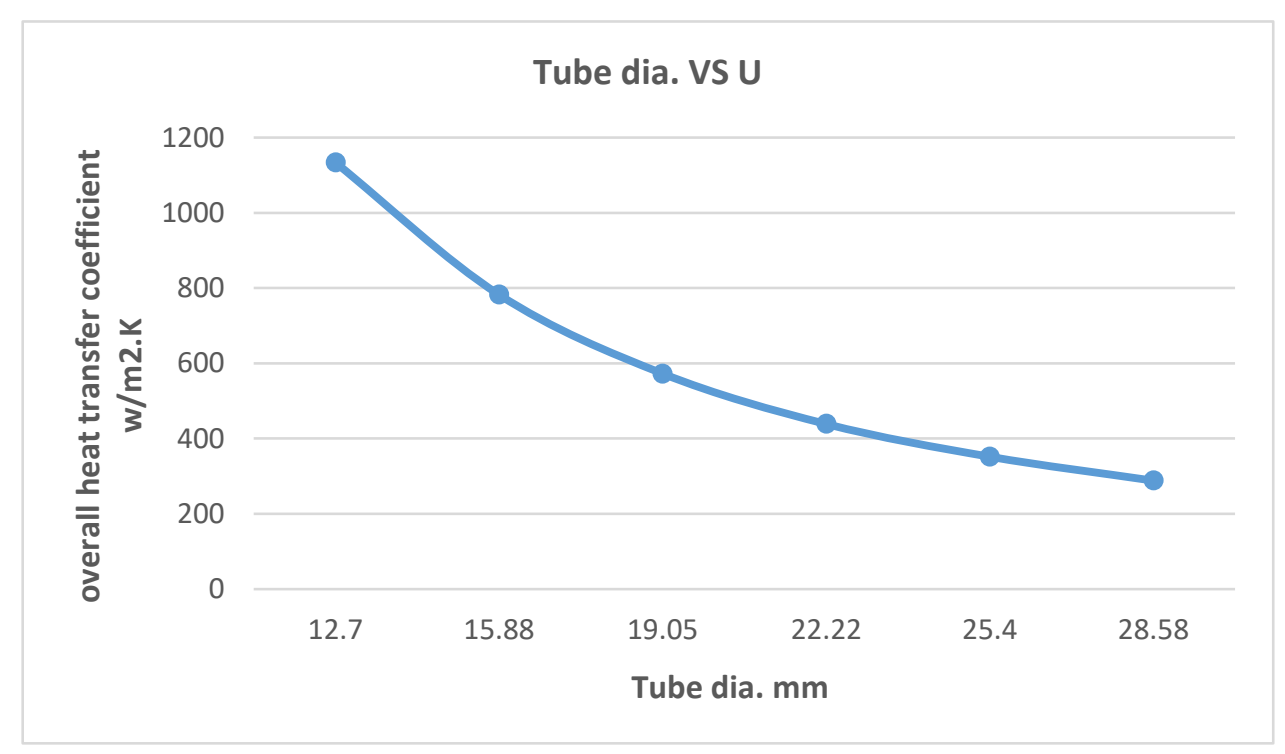

Fig. (3): Tubes Diameter and Its Relation With Overall Heat Transfer Coefficient

3.2 Effect of Reboiler metal: The difference in the metal of the reboiler has a great impact on the design due to the difference in the overall heat transfer coefficient for each metal as well the huge impact 
on the cost as shown in Appendix (2) which clarify how the change in the metal effect on the overall cost of the reboiler which is calculated by the simulation in the EDR. While table (5) shows the effect of the change in the metal of the tubes on the heat exchanged, the mean temperature difference, the cost of the tubes, and the overall cost, on other hand, it doesn't affect the area and the number of tubes.

Table 5: Tubes Metal Change and Its Effects.

\begin{tabular}{|c|c|c|c|c|c|c|}
\hline Tube Metal & $\begin{array}{c}\text { Area } \\
\mathbf{m}^{\mathbf{2}}\end{array}$ & $\begin{array}{c}\text { Heat Exchanged } \\
\mathbf{k W}\end{array}$ & $\begin{array}{c}\text { NO. Of } \\
\text { Tubes }\end{array}$ & $\begin{array}{c}\text { Tube Metal Cost } \\
\mathbf{U S D \$}\end{array}$ & $\begin{array}{c}\text { Total Cost } \\
\mathbf{U S D \$}\end{array}$ & $\begin{array}{c}\mathbf{U} \\
\mathbf{W} / \mathbf{m}^{\mathbf{2}} \mathbf{. K}\end{array}$ \\
\hline Carbon steel & 62.3 & 2094.3 & 200 & 3344 & 277024 & 361.7 \\
\hline SS-304 & 62.3 & 2088.5 & 200 & 8101 & 245880 & 353.6 \\
\hline Titanium & 62.3 & 2087.5 & 200 & 66402 & 914185 & 352.3 \\
\hline 3.5 Ni steel & 62.3 & 2093.6 & 200 & 23601 & 374867 & 360.9 \\
\hline Copper & 62.3 & 2098.3 & 200 & 17300 & 661960 & 368.07 \\
\hline Aluminum 3003 & 62.3 & 2097.8 & 200 & 2955 & 436003 & 367.3 \\
\hline Al-Ni Bronze & 62.3 & 2097.1 & 200 & 43080 & 799506 & 366.5 \\
\hline SS-321 & 62.3 & 2088.1 & 200 & 212390 & 317340 & 353.03 \\
\hline
\end{tabular}

From Figure (4), which shows the heat exchanged when changing the tube metal, and Figure (5) which shows the reboiler metal (the shell and tubes) against the cost, it is possible to choose the best type of metal that meets the requirements of the reboiler process and the lowest total cost. In addition, consideration must be given to values of the overall heat transfer coefficient which shows in Figure (6) for choosing the best metal for the design. Obviously, by comparing the cost with the values of the heat transfer coefficient, it becomes clear that cast iron is the best choice.

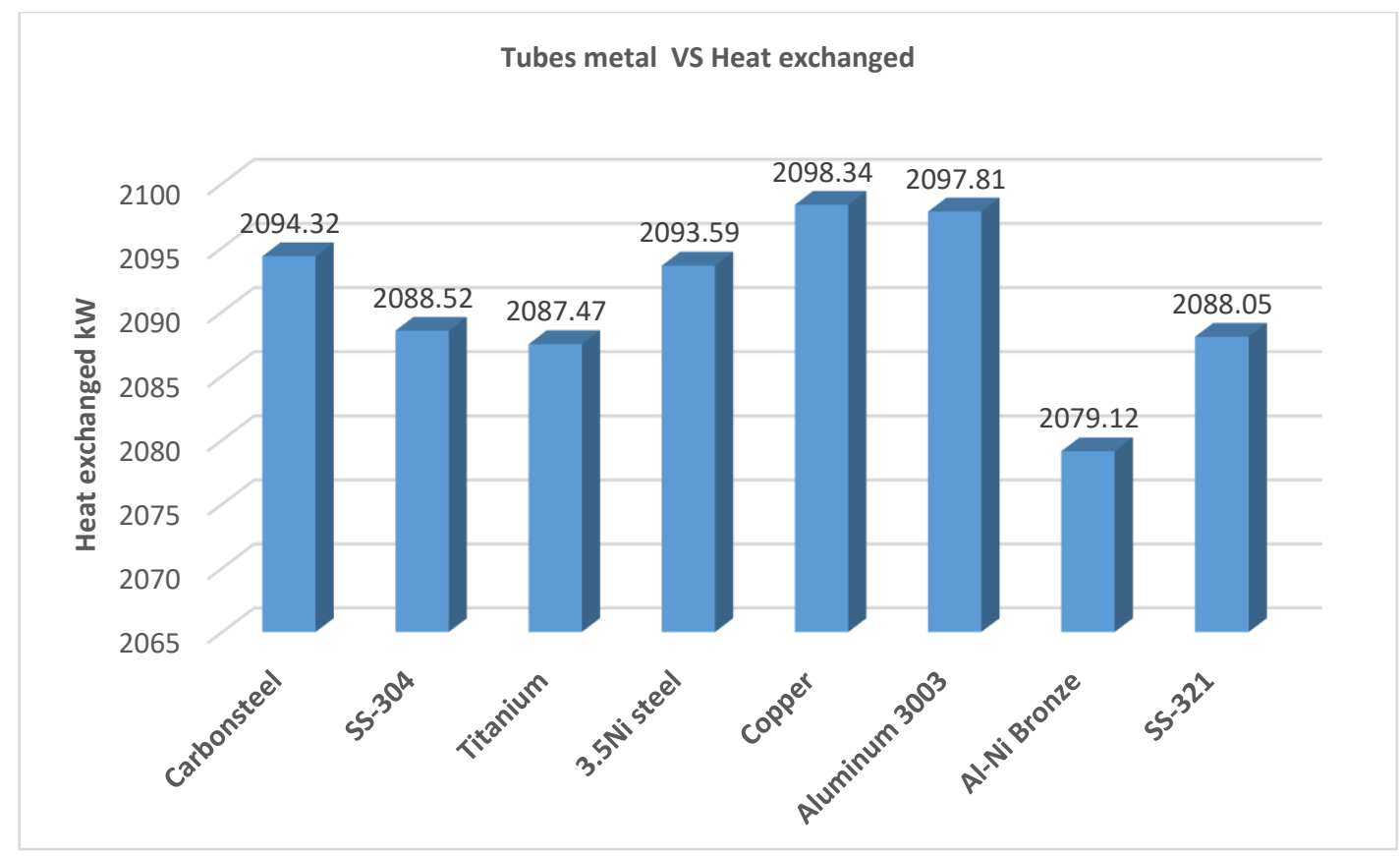

Fig. (4): Tubes Metal and Its Relation With Heat Exchanged. 


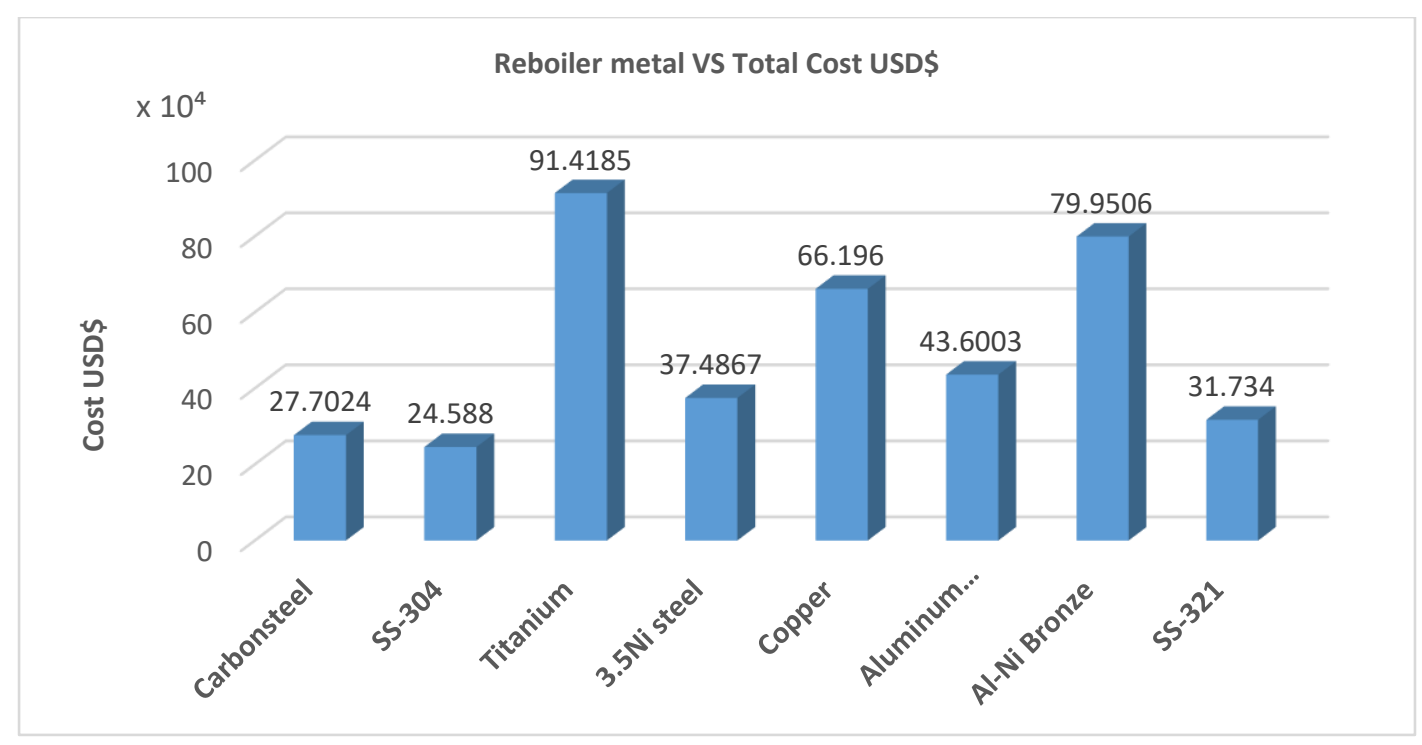

Fig. (5): Reboiler Metal and Its Relation with the Total Cost

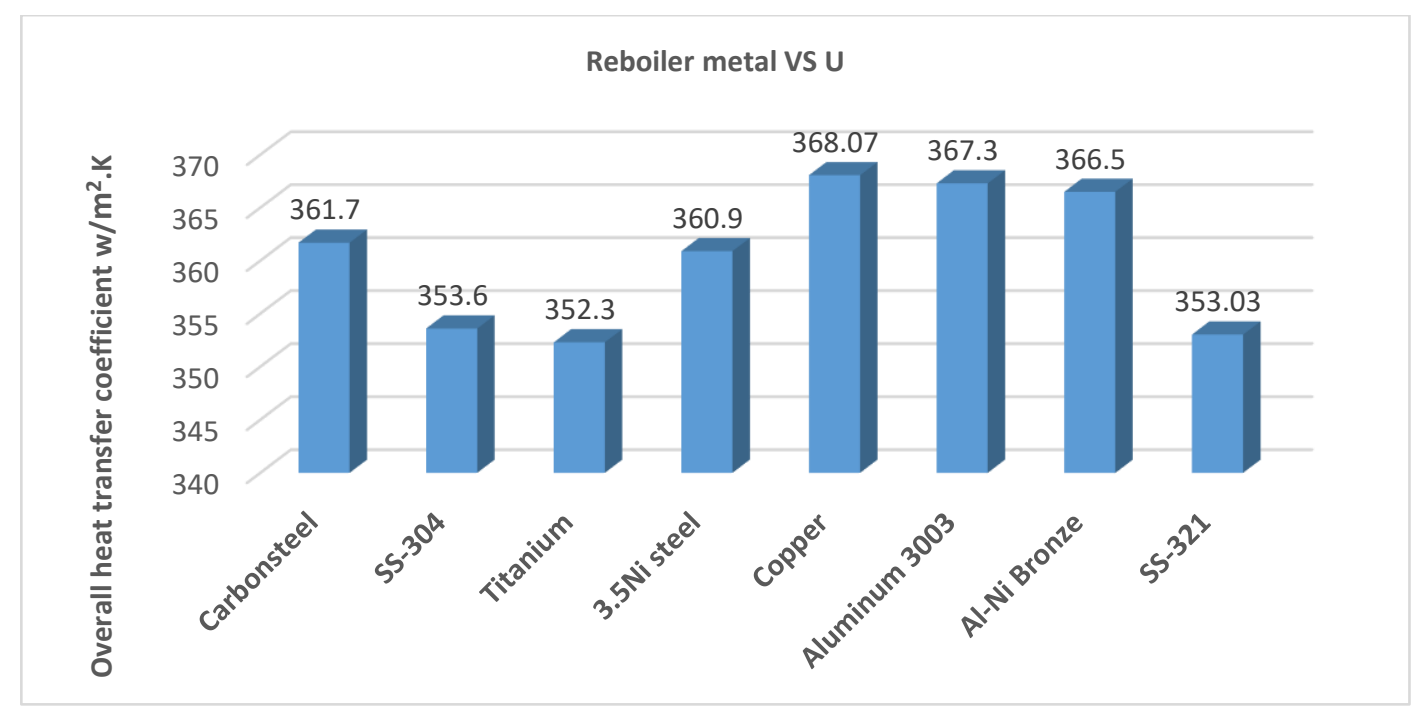

Fig. (6): Reboiler Metal and Its Relation with the Overall Heat Transfer Coefficient.

3.3 Effect of Mass flow rate: When the flow rate of the vapor in the hot stream increases, as showing in Figure (7), it is clear that the change is directly proportional, the heat exchange increases with the same design diameter of the tube, reaching a flow rate of $5 \mathrm{~kg} / \mathrm{s}$ the warning of vibration appears, after access this flow rate and getting the $6 \mathrm{~kg} / \mathrm{s}$ there is a failure in the implementation of the program due to the problems of vibration, therefore increasing the flow with the acceptable range will be enhancing the heat duty.

The same change in the mass flow rate was done and found the affected on the temperature of the hot out and cold out streams in the simulations, as shown in Figures (8) and (9), the same failure was found after passing $4 \mathrm{~kg} / \mathrm{s}$ because the problem of vibration and also the overall heat transfer coefficient will decrease, the result of the simulation discovered that the relationship was direct within the specified acceptable flow range and depend on the result shows in Figures (10) it's clear that the best flow is $4 \mathrm{~kg} / \mathrm{s}$. The increase in the flow rate leads to an increase in the flowing's: fluid velocity, Reynolds number, Nusselt number. Consequently, an increase in the overall heat transfer coefficient has resulted. 


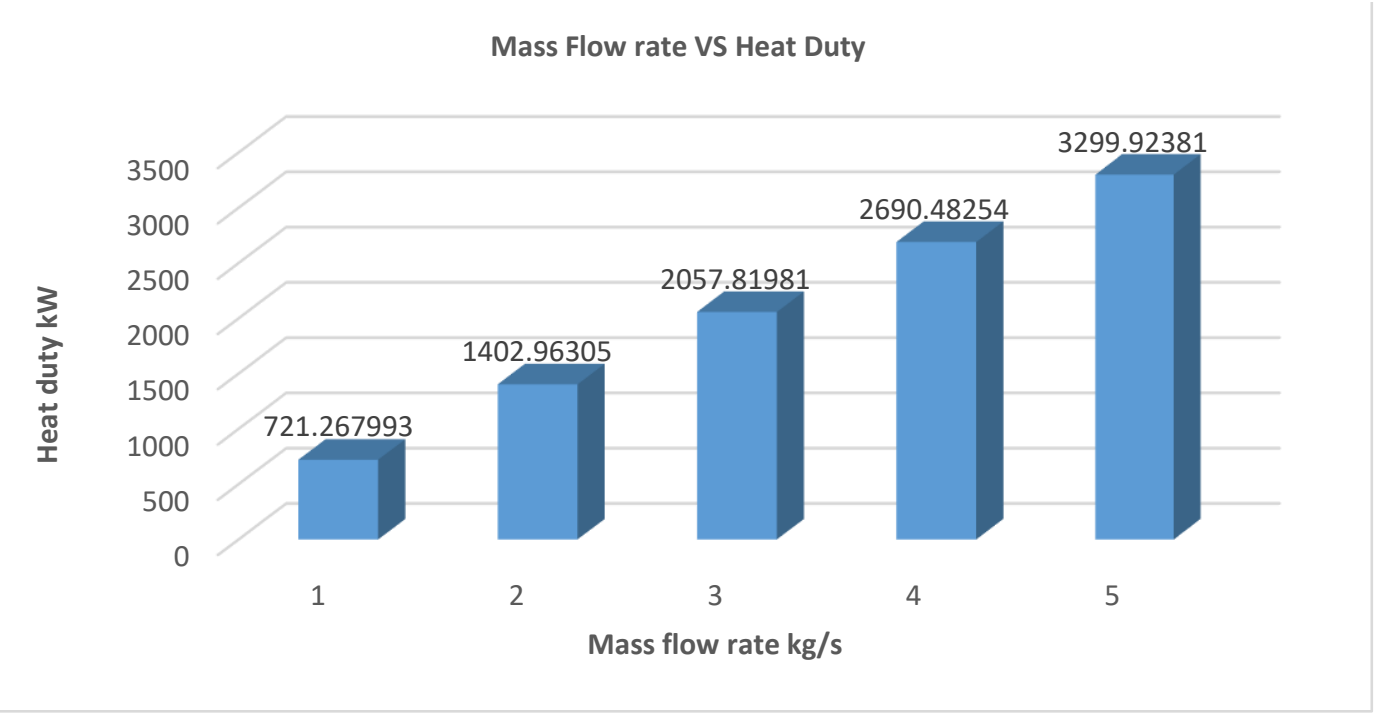

Fig. (7): Mass Flow Rate Change and Its Effect On Heat Duty

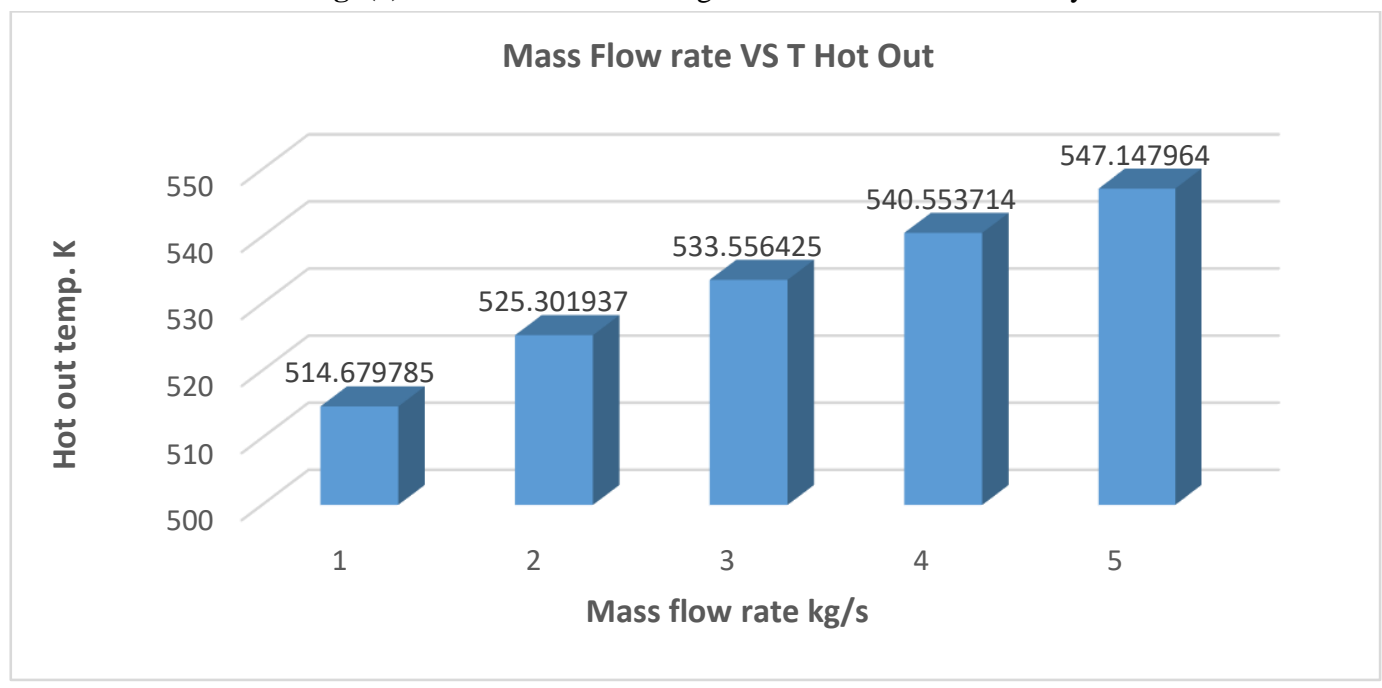

Fig. (8): Mass Flow Rate Change and Its Effect On The Temperature Of Hot Out

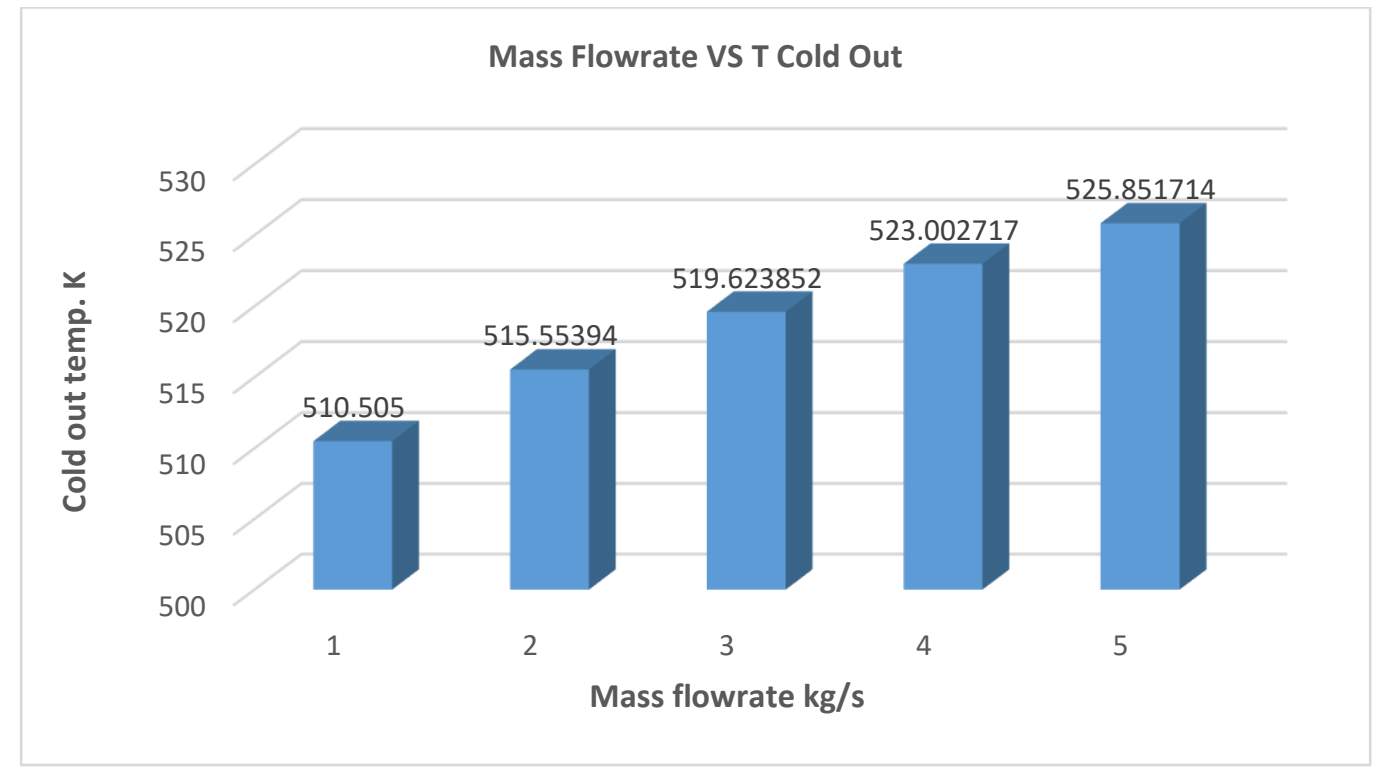

Fig. (9): Mass Flow Rate Change and Its Effect On The Temperature Of Cold. 


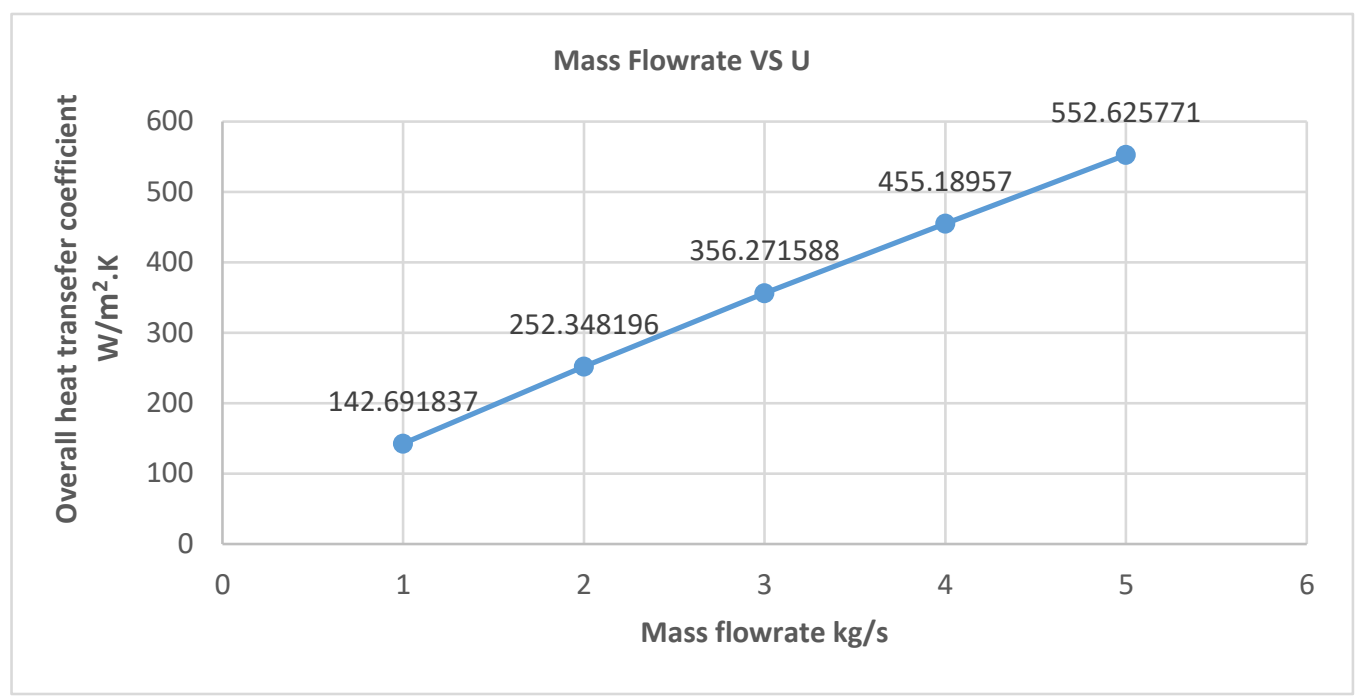

Fig. (10): Mass Flow Rate Change and Its Effect On The Overall Heat Transfer Coefficient.

3.4 Effect of inlet shell-side temperature: The effect of the temperature is very important to do the suitable design for the reboiler, while the temperature of the inlet of cold streams change when the simulation was done, it was affected the overall heat transfer coefficient, as shown in Figure (11) it's clear that when increasing the temperature of the cold stream from $473 \mathrm{k}$ (an increase of 5 degrees whenever doing the simulation) until it reaches $503 \mathrm{k}$ its effect on the overall heat transfer coefficient, and also the figure shows the best temperature that can be used to improve the efficiency which it is $493 \mathrm{k}$, while all the other operating condition remains as it is. In the same topic, Figure (12) shows the relationship between the tube length and the bulk temperature, which describes the bulk temperature distribution along the tube and the tube metal side temperature and tube side fouling surface temperature distribution along the tube.

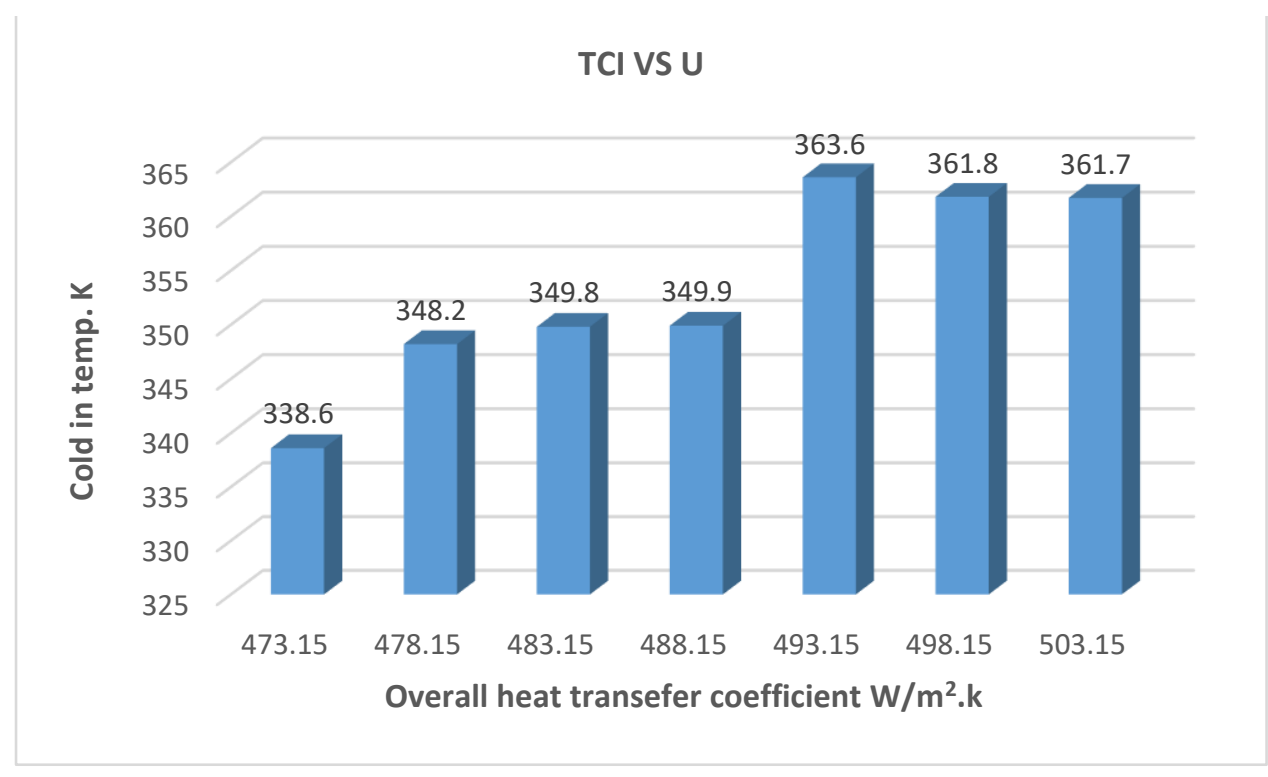

Fig. (11): The Change of the Cold Stream Inlet Temperature and Its Effect on the Overall Heat Transfer Coefficient. 


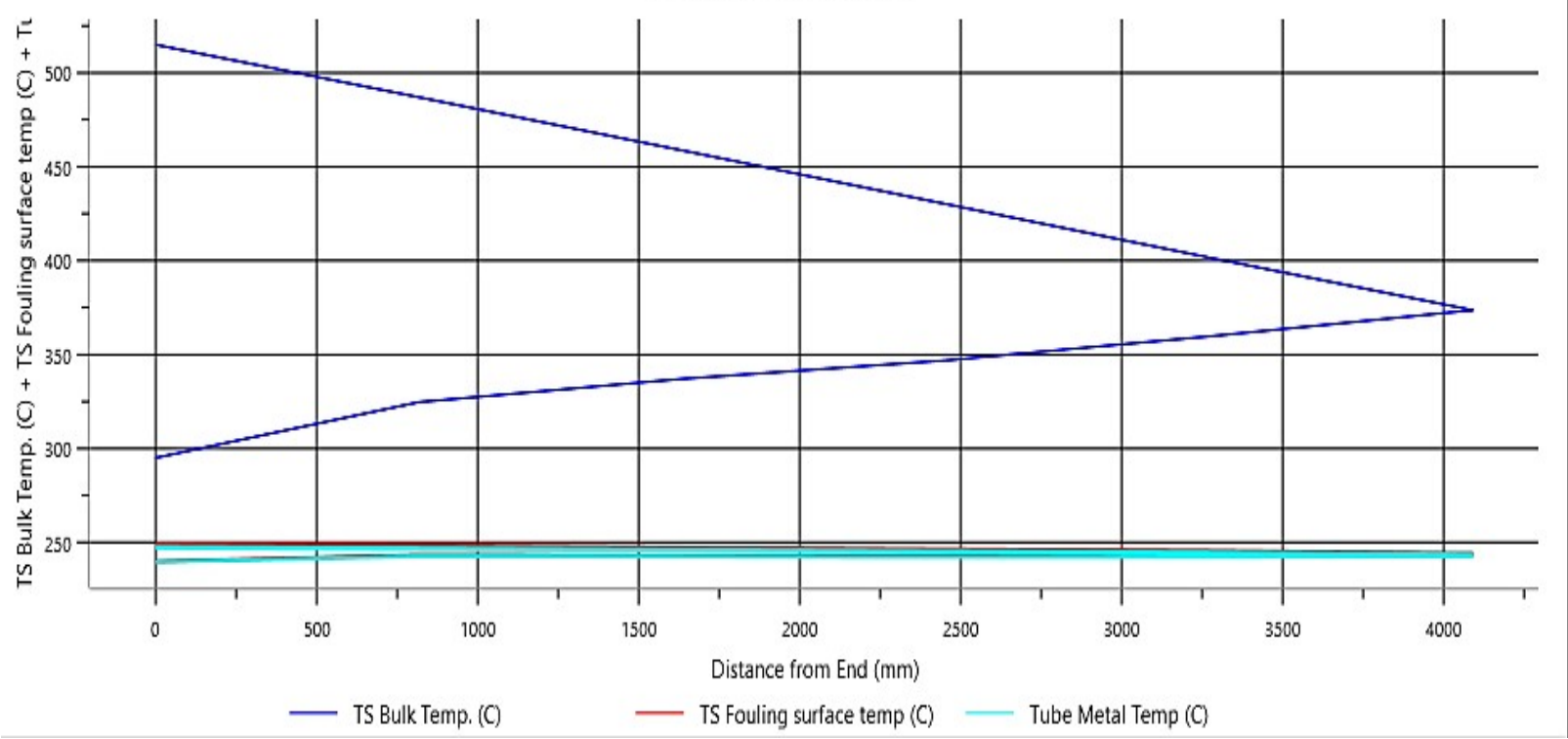

Fig. (12): The Change of Tube Side Temperature, Tube Side Bulk Temperature, and Tube Side Fouling Surface Temperature Distribution Along the Tube

\section{General Notes for Kettle Reboiler Design:}

1- For the predicted maximum flow, a safety coefficient of 0.7 is utilized.

2- To prevent vapor coverage, a tube pitch from 1,5-2,0 times the exterior diameter of the tube must be utilized.

3- tall narrow bundles are more effective than tiny chubby bundles.

4- The shell must be designed so that the vapor and the liquids may be disengaged. The necessary shell radius depends on the heat flow

5- At a minimum of $0.25 \mathrm{~m}$ space must be the float between both the fluid and the shell.

6- When a low vapor flow rate is needed, a vertical, cylindrical container must be used with a coil or heated jacket

7- If the temp fluctuates on both sides, it is essential to adjust the logarithmic difference in temperatures for variations in actual cross or counter-current flows.

8- The mean temperature difference must always be dependent on the boiling point of the fluid if the feeding is under-cooled.

\section{Conclusion}

Kettles reboiler heat exchanger was simulate using Aspen Plus and Aspen EDR to study the effect of the operation condition variables and choosing the optimum design specification at the lowest cost that was calculated by using Aspen EDR. By doing so, the optimization method can be divided into two steps:

1- Enhancing the model and its operating conditions by providing the optimal temperature and mass flow rates. This affected directly on the overall heat transfer coefficient yields to provide a clear indication of the efficiency.

By determining the optimal operating conditions which are $493.15 \mathrm{k}$ for the cold stream inlet temperature and $4 \mathrm{~kg} / \mathrm{s}$ for the hot stream flow rate of the reboiler. While performing the simulation above, it was found that the overall heat transfer coefficient has been positively increased by $28.27 \%$.

2- By selecting the best suitable tube diameter as well as the best type of metal utilized, the best appropriate design and its influence on cost were investigated.

The optimum tube diameter was $25.4 \mathrm{~mm}$, and the suitable tube metal was carbon steel, by using the Aspen EDR program for calculating their effect on the cost. 
NOMENCLATURE

\begin{tabular}{|c|c|c|}
\hline Symbol & Definition & Unit \\
\hline $\mathrm{P}$ & Pressure & bar \\
\hline $\mathrm{T}$ & Temperature & $\mathrm{k}$ \\
\hline$\lambda$ & Latent heat & $\mathrm{kJ} / \mathrm{kg}$ \\
\hline $\mathrm{m}^{\circ}$ & Mass flow rate & $\mathrm{Kg} / \mathrm{s}$ \\
\hline$\rho$ & Density & $\mathrm{kg} / \mathrm{m}^{3}$ \\
\hline$\mu$ & Viscosity & N.s $/ \mathrm{m}^{2}$ \\
\hline $\mathrm{K}_{\mathrm{w}}$ & Thermal conductivity & $\mathrm{W} / \mathrm{m} . \mathrm{k}$ \\
\hline $\mathrm{c}_{\mathrm{p}}$ & Specific heat & kJ/kg.k \\
\hline $\mathrm{P}_{\mathrm{c}}$ & Critical Pressure & bar \\
\hline$\varnothing$ & Heat duty & $\mathrm{kW}$ \\
\hline $\mathrm{F}$ & Correction factor & Dimensionless \\
\hline A & Exchanger required area & $\mathrm{m}$ \\
\hline $\mathrm{U}_{0}$ & Overall heat transfer coefficient & $\mathrm{W} / \mathrm{m}^{2} \cdot \mathrm{k}$ \\
\hline $\mathrm{Nt}$ & No. of Tubes & Dimensionless \\
\hline Do & Outside tube diameter & $\mathrm{m}$ \\
\hline $\mathrm{L}$ & Tube length & $\mathrm{m}$ \\
\hline $\mathrm{Np}$ & Number of tubes pass & Dimensionless \\
\hline $\mathrm{AC}$ & Cross-section area & $\mathrm{m}$ \\
\hline Di & Inside tube diameter & $\mathrm{m}$ \\
\hline $\mathrm{V}$ & Velocity in tubes & $\mathrm{m} / \mathrm{s}$ \\
\hline $\operatorname{Re}$ & Reynolds Number & Dimensionless \\
\hline$h_{0}$ & Shell side boiling coefficient & $\mathrm{W} / \mathrm{m}^{2} \cdot \mathrm{k}$ \\
\hline $\mathrm{pr}$ & Prandtl Number & Dimensionless \\
\hline$h i$ & Tube side heat transfer coefficient & $\mathrm{W} / \mathrm{m}^{2} \cdot \mathrm{k}$ \\
\hline
\end{tabular}

\section{LIST OF ABBREVIATIONS}

\begin{tabular}{|c|c|}
\hline Abbreviation & Definition \\
\hline HEs & Heat exchanger \\
\hline TEMA & Tubular Exchanger Manufacturers Association \\
\hline LMTD & Log Mean Temperature Difference \\
\hline EDR & Exchanger Design and Rating \\
\hline $\mathrm{Nt}$ & No. of Tubes \\
\hline $\mathrm{Np}$ & Number of tubes pass \\
\hline $\mathrm{Re}$ & Reynolds Number \\
\hline $\mathrm{Pr}$ & Prandtl Number \\
\hline
\end{tabular}


Appendix (1): Reboiler diameter change and its cost effects by EDR simulation.

\begin{tabular}{|c|c|c|c|c|c|}
\hline \multicolumn{2}{|c|}{ Tube dia. } & & & & \\
\hline \multirow{8}{*}{0.5} & \multirow{8}{*}{12.7} & Weights & $\mathrm{kg}$ & Cost data & Dollar(US) \\
\hline & & Shell & 33658.4 & Labor cost & 174586 \\
\hline & & Front head & 7744.3 & Tube material cost & 1518 \\
\hline & & Rear head & 0 & Manerial cost (except tubes) & 99077 \\
\hline & & Shell cover & & & \\
\hline & & Bundle & 4306.1 & & \\
\hline & & Total weight - empty & 45708.8 & Total cost (1 shell) & 275181 \\
\hline & & Total weight - filed with water & 56375.6 & Total cost (all shells) & 275181 \\
\hline \multirow{8}{*}{0.625} & \multirow{8}{*}{15.88} & Weights & $\mathrm{kg}$ & Cost data & Dollar(US) \\
\hline & & Shell & 33658.4 & Labor cost & 174650 \\
\hline & & Front head & 7744.3 & Tube material cost & 1990 \\
\hline & & Rear head & 0 & Material cost (except tubes) & 99087 \\
\hline & & Shell cover & & & \\
\hline & & Bundle & 4439.1 & & \\
\hline & & Total weight - empty & 45841.8 & Total cost (1 shell) & 275727 \\
\hline & & Total weight - flled with water & 564917 & Total cost (alt shels) & 275727 \\
\hline \multirow{8}{*}{0.75} & \multirow{8}{*}{19.05} & Weights & $\mathrm{kg}$ & Cost data & Dollar(US) \\
\hline & & Shell & 33658.4 & Labor cost & 174695 \\
\hline & & Front head & 77443 & Tube material cost & 2461 \\
\hline & & Rear head & 0 & Material cost (except tubes) & 99097 \\
\hline & & Shell cover & & & \\
\hline & & Bundle & 45632 & & \\
\hline & & Total weight - empty & 459659 & Total cost (1 shell) & 276254 \\
\hline & & Total weight - filed with water & 565999 & Total cost (at shells) & 276254 \\
\hline \multirow{8}{*}{0.875} & \multirow{8}{*}{22.22} & Weights & $k_{9}$ & Cost data & Dollar(US) \\
\hline & & Shell & 33658.4 & Labor cost & 174698 \\
\hline & & Front head & 7744.3 & Tube material cost & 2933 \\
\hline & & Rear head & 0 & Material cost (except tubes) & 98949 \\
\hline & & Shel cover & & & \\
\hline & & Bundle & 4626.2 & & \\
\hline & & Total weight - empty & 46029 & Total cost (1 shell) & 276580 \\
\hline & & Total weight - filled with water & 56655 & Total cost (al shela) & 276580 \\
\hline \multirow{8}{*}{1} & \multirow{8}{*}{25.4} & Weights & $\mathrm{kg}$ & Cost data & Dollar(US) \\
\hline & & Shell & 33658.4 & Labor cost & 174725 \\
\hline & & Front head & 7744.3 & Tube material cost & 3404 \\
\hline & & Rear head & 0 & Material cost (except tubes) & 98959 \\
\hline & & Shell cover & & & \\
\hline & & Bundle & 4733,7 & & \\
\hline & & Total weight - empty & 461365 & Total cost (1 shell) & 277088 \\
\hline & & Total weight - flled with water & 56748.8 & Total cost (all shels) & 277088 \\
\hline \multirow{8}{*}{1.125} & \multirow{8}{*}{28.58} & \begin{tabular}{|l|} 
Weights \\
\end{tabular} & $\mathrm{kg}$ & Cost data & Dollar(US) \\
\hline & & Shell & 336584 & Labor cost & 174868 \\
\hline & & Front head & 7744.3 & Tube material cost & 3874 \\
\hline & & Rear head & 0 & Material cost (ercept tubes) & 98970 \\
\hline & & Shell cover & & & \\
\hline & & Bundle & 48325 & & \\
\hline & & Total weight - empty & 462352 & Total cost (1 sheil) & 277712 \\
\hline & & Total weight - flled with water & 56834.9 & Total cost (all sheils) & 277712 \\
\hline
\end{tabular}


Appendix (2): Reboiler metal change and its cost effects by EDR simulation.

\begin{tabular}{|c|c|c|c|c|}
\hline Tube material & & & & \\
\hline & Weights & $\mathrm{kg}$ & Cost data & Dollar(US) \\
\hline & Shell & 33658.4 & Labor cost & 174722 \\
\hline & Front head & 7744.3 & Tube material cost & 3344 \\
\hline Carbonsteel & Rear head & 0 & Material cost (except tubes) & 98958 \\
\hline Carbonsteel & Shell cover & & & \\
\hline & Bundle & 4720.7 & & \\
\hline & Total weight - empty & 46123.4 & Total cost ( 1 shell) & 277024 \\
\hline & Total weight - filled with water & 567371 & Total cost (all shells) & 277024 \\
\hline & Weights & $\mathrm{kg}$ & Cost data & Dollar(US) \\
\hline & Shell & 8813.5 & Labor cost & 93685 \\
\hline & Front head & 4131.3 & Tube material cost & 8101 \\
\hline SS-304 & Rear head & 0 & Material cost (except tubes) & 144094 \\
\hline SS-304 & Shell cover & & & \\
\hline & Bundle & 4784 & & \\
\hline & Total weight - empty & 17728.9 & Total cost ( 1 shell) & 245880 \\
\hline & Total weight - filled with water & 28342.8 & Total cost (all shells) & 245880 \\
\hline & Weights & $\mathrm{kg}$ & Cost data & Dollar(US) \\
\hline & Shell & 14851.6 & Labor cost & 114826 \\
\hline & Front head & 6502.8 & Tube material cost & 17300 \\
\hline Conner & Rear head & 0 & Material cost (except tubes) & 529834 \\
\hline copper & Shell cover & & & \\
\hline & Bundle & 5440.3 & & \\
\hline & Total weight - empty & 26794.7 & Total cost (1 shell) & 661960 \\
\hline & Total weight - filled with water & 37402.2 & Total cost (all shells) & 661960 \\
\hline & Weights & $\mathrm{kg}$ & Cost data & Dollar(US) \\
\hline & Shell & 26631.3 & Labor cost & 174894 \\
\hline & Front head & 13093.9 & Tube material cost & 2955 \\
\hline Aluminum 3003 & Rear head & 0 & Material cost (except tubes) & 258154 \\
\hline Aluminum 3003 & Shell cover & & & \\
\hline & Bundle & 1666.3 & & \\
\hline & Total weight - empty & 41391.5 & Total cost (1 shell) & 436003 \\
\hline & Total weight - filled with water & 52005.5 & Total cost (all shells) & 436003 \\
\hline & Weights & $\mathrm{kg}$ & Cost data & Dollar(US) \\
\hline & Shell & 8547.1 & Labor cost & 88283 \\
\hline & Front head & 2944.4 & Tube material cost & 66402 \\
\hline Titanium & Rear head & 0 & Material cost (except tubes) & 759500 \\
\hline IItanium & Shell cover & & & \\
\hline & Bundle & 2745.4 & & \\
\hline & Total weight - empty & 14236.9 & Total cost (1 shell) & 914185 \\
\hline & Total weight - filled with water & 24844.4 & Total cost (all shells) & 914185 \\
\hline & Weights & $\mathrm{kg}$ & Cost data & Dollar(US) \\
\hline & Shell & 6471.3 & Labor cost & 82207 \\
\hline & Front head & 3717.3 & Tube material cost & 23601 \\
\hline $35 \mathrm{Ni}$ steel & Rear head & 0 & Material cost (except tubes) & 269059 \\
\hline & Shell cover & & & \\
\hline & Bundle & 4665.7 & & \\
\hline & Total weight - empty & 14854.2 & Total cost (1 shell) & 374867 \\
\hline & Total weight - filled with water & 25468.2 & Total cost (all shells) & 374867 \\
\hline & Weights & $\mathrm{kg}$ & Cost data & Dollar(US) \\
\hline & Shell & 10805.6 & Labor cost & 94486 \\
\hline & Front head & 4183.9 & Tube material cost & 43080 \\
\hline Al-Ni Bronze & Rear head & 0 & Material cost (except tubes) & 661939 \\
\hline Al-INI Bronze & Shell cover & & & \\
\hline & Bundle & 4530.8 & & \\
\hline & Total weight - empty & 19520.2 & Total cost (1 shell) & 799506 \\
\hline & Total weight - filled with water & 30127.7 & Total cost (all shells) & 799506 \\
\hline & Weights & $\mathrm{kg}$ & Cost data & Dollar(US) \\
\hline & Shell & 9248.6 & Labor cost & 95164 \\
\hline & Front head & 4193.6 & Tube material cost & 9786 \\
\hline SS-321 & Rear head & 0 & Material cost (except tubes) & 212390 \\
\hline $30-321$ & Shell cover & & & \\
\hline & Bundle & 4784 & & \\
\hline & Total weight - empty & 18226.2 & Total cost (1 shell) & 317340 \\
\hline & Total weight - filled with water & 28840.1 & Total cost (all shells) & 317340 \\
\hline
\end{tabular}




\section{References}

[1] S. P. C, J. Parikh, and D. Jain, ““ Design of A Vertical Thermosyphon Reboiler ,” 1995.

[2] B. Kilkovsky, J. Kohoutek, Z. Jegla, and P. Stehlik, "Software application for supporting of CAE in process engineering: Automated choice of the suitable reboiler type," Chem. Eng. Trans., vol. 18, no. January 2009, pp. 821-826, 2009, doi: 10.3303/CET0918134.

[3] Y. Susmiati, B. Purwantana, N. Bintoro, and S. Rahayoe, "Design and testing of vertical tubular baffle heat exchanger as an internal reboiler in the distillation device," IOP Conf. Ser. Earth Environ. Sci., vol. 355, no. 1, 2019, doi: 10.1088/1755-1315/355/1/012001.

[4] R. Goedecke and S. Scholl, "Modelling and simulation of a pillow plate thermosiphon reboiler," Heat Mass Transf. und Stoffuebertragung, vol. 55, no. 1, pp. 95-104, 2019, doi: 10.1007/s00231-01802543-4.

[5] D. A. McNeil, K. Bamardouf, and B. M. Burnside, "A one-fluid, two-dimensional flow simulation model for a kettle reboiler," Int. J. Heat Mass Transf., vol. 53, no. 5-6, pp. 825-835, 2010, doi: 10.1016/j.ijheatmasstransfer.2009.11.042.

[6] D. A. McNeil, K. Bamardouf, B. M. Burnside, and M. Almeshaal, "Investigation of flow phenomena in a kettle reboiler," Int. J. Heat Mass Transf., vol. 53, no. 5-6, pp. 836-848, 2010, doi: 10.1016/j.ijheatmasstransfer.2009.11.041

[7] M. Pezo, V. Stevanovic, and Z. Stevanovic, "Simulations of the kettle reboiler shell side thermalhydraulics with different two-phase flow models," Therm. Sci., vol. 10, no. 2, pp. 127-140, 2006, doi: 10.2298/tsci0602127p.

[8] S. Kumar, A. Jain, B. Mohanty, and S. C. Gupta, "Recirculation model of kettle reboiler," Int. J. Heat Mass Transf., vol. 46, no. 15, pp. 2899-2909, 2003, doi: 10.1016/S0017-9310(03)00015-2.

[9] S. Arneth and J. Stichlmair, "Characteristics of thermosiphon reboilers," Int. J. Therm. Sci., vol. 40, no. 4, pp. 385-391, 2001, doi: 10.1016/S1290-0729(01)01231-5.

[10] B. M. Burnside, K. M. Miller, D. A. McNeil, and T. Bruce, "Heat transfer coefficient distributions in an experimental kettle reboiler thin slice," Chem. Eng. Res. Des., vol. 79, no. 4, pp. 445-452, 2001, doi: 10.1205/026387601750282373.

[11] S. S. Parhi, G. P. Rangaiah, and A. K. Jana, "Optimizing reboiler duty and reflux ratio profiles of vapor recompressed batch distillation," Sep. Purif. Technol., vol. 213, no. December 2018, pp. 553570, 2019, doi: 10.1016/j.seppur.2018.12.066.

[12] F. Kamişli and A. A. Ahmed, "Simulation and Optimization of A Crude Oil Distillation Unit Ham Petrol D amitma Ünitesinin Simülasyonu ve Optimizasyonu," vol. 14, no. 2, pp. 59-68, 2019.

[13] Y. Zhou and J. Yu, "Optimization design of falling film type plate-fin condenser/reboilers by minimizing specific entropy generation rate," Cryogenics (Guildf)., vol. 99, pp. 25-31, 2019, doi: 10.1016/j.cryogenics.2019.02.006.

[14] S. . Thakore and B. . Bhatt, Introduction to Process Engineering and Design, vol. 91. 2007. 